\title{
Sex differences in the emotional behavior of three strains of laboratory rat*
}

\author{
JOHN ARCHER \\ Ethology and Neurophysiology Group, School of Biological Sciences \\ University of Sussex, Falmer, Brighton, Sussex, United Kingdom
}

\begin{abstract}
Sex differences in the emotional behavior of three strains of rats were investigated, using a variety of measures taken during the initial 2 min of open-field exposure and after a loud bell had sounded. Animals were tested either in a clean open field or in one containing the odor of a same-sex conspecific. No general overall sex differences for a variety of measures associated with emotional reactivity were found, so the results did not supporf the theory that male rats are more "emotional" than females. Sex differences for particular measures associated with emotional responsiveness were found, but these varied with the strain, measure, and odor condition: The latter was found to be particularly important.
\end{abstract}

Sex differences in the behavior of rodents in novel environments and to other test situations for "emotional" behavior have been frequently reported in the literature. Typically, females show more ambulation and less defecation in an open field (e.g., Broadhurst, 1957, 1958; Henderson, 1963; Gray, Levine, \& Broadhurst, 1965), they emerge sooner from their home cage into a novel environment (e.g., Meyers, 1962; Woods, 1962; Pfaff \& Zigmond, 1971), and they show faster acquisition of a shuttlebox avoidance learning task (studies reviewed by Gray, 1971; Beatty \& Beatty, 1970) than do males. Gray (1971) interpreted these and other results as supporting the hypothesis that male rodents were more fearful than females.

Gray's theory was criticized by the present author (Archer, 1971) on several grounds. One of these was that sex differences in open-field measures were more variable than Gray suggested, strain differences being a particularly important determinant of this variation. Another criticism was that the commonly used open-field measures (ambulation and defecation) were equivocal, since their hypothetical inverse relationship is found in only some, but not all, studies involving the appropriate correlation data. It was further suggested (Archer, 1973) that variables other than emotional reactivity could influence these measures, e.g., ambulation could, under different circumstances, reflect causally different types of behavior (e.g., lack of "freezing," presence of escape behavior, lack of lying or sitting, or lack of sniffing at localized stimuli). A fuller discussion of these and related issues is included in Archer (1973).

Odors are particularly important in the social behavior of rodents (review by Cheal \& Sprott, 1971). With a few recent exceptions (Whittier \& McReynolds, 1965; Stevens \& Koster, 1972; Davies \& Bellamy, 1972), little attempt has been made in open-field studies to control

\footnotetext{
*Supported by a grant from the Medical Research Council of the United Kingdom to R. J. Andrew. I thank Professor Andrew for his helpful comments on this paper.
}

for the possibility that a previously tested animal might influence the behavior of a currently tested one.

The present paper describes an investigation of sex differences in the emotional behavior of rats in an open-field test, modified to overcome some of the limitations suggested above. Several methodological changes were introduced compared with previous work: First, three strains were used, so that general and strain-specific sex differences could be distinguished. Second, a range of measures of emotional behavior, rather than merely ambulation and defecation, were used: These included escape behavior, reluctance to leave the walls of the open field, and defecation and freezing under two different circumstances. They were chosen as providing a range of behavior associated with "emotional responsiveness;" thus, sex differences could be studied in more detail than on the basis of the more usual ambulation and defecation measures. Third, the present work provided separate data for rats tested in a clean (odor-free) open field and for rats tested in a field containing an odor from the same sex and strain. Thus, any effect of differential responsiveness to odors of the same-sex conspecific was not confounded with differential responsiveness to the open-field situation, as may have occurred in many previous studies.

\section{METHOD}

Adult male and female rats, 60 of each sex, aged 2-3 months, and housed five to a cage, were each tested once in an open field. The sample of rats comprised 40 Sprague-Dawley (albino), 40 Wistar (albino), and 40 Long-Evans (hooded) strains. Two open fields were used, both of the type described by Broadhurst (1957). The procedure involved testing two male rats from the same strain consecutively in one open field and two females, also from the same strain, consecutively in the other open field on each day. The floors of both open fields were then washed. Thus, the first rat tested on any particular day was exposed to a relatively clean apparatus (henceforth termed the NOD, or "no odor," condition), whereas the second rat was exposed to a field containing the recently deposited odor of a conspecific (only the feces were removed); this will be referred to as the $O D$, or "odor," condition.

The testing procedure (described in Archer, 1973) involved a 


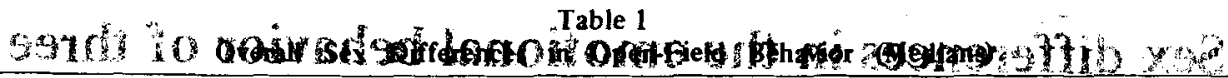

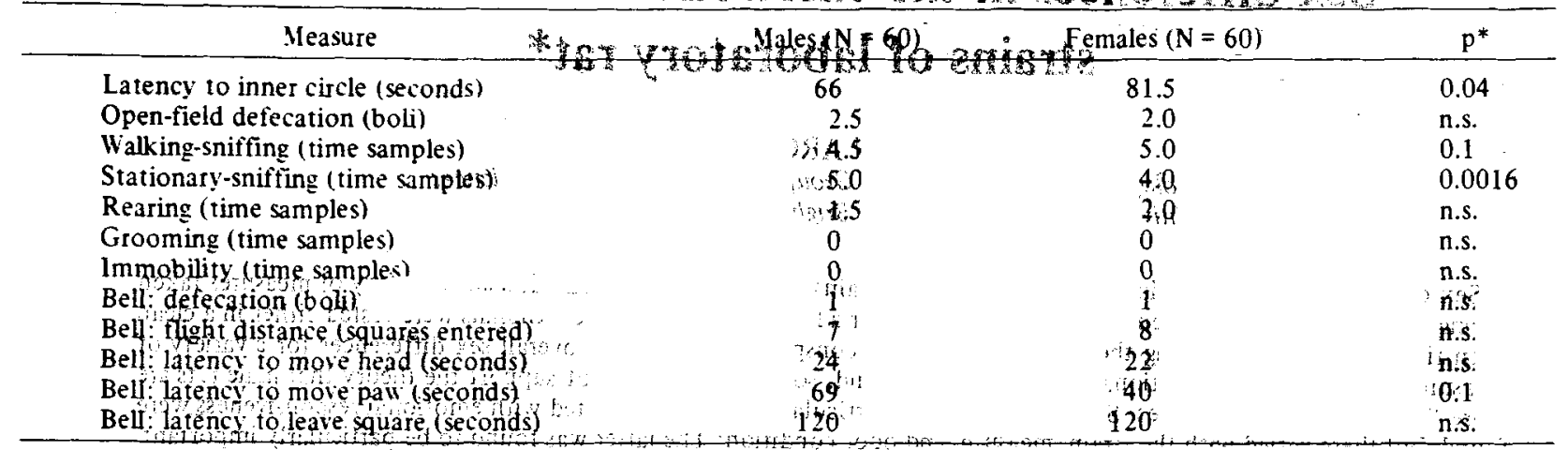

*Wilcoxon matchet'-pairs test. two-tailed probabilities (Siegel. 1956).

2-min exposure to the open field followed by the tinging of a

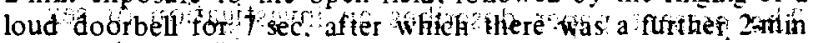
observation' periodi The measures taken were, fitstritime, samples every! 10-see of behavior accurring during the first 2 min expasure classified as Walking and sniffing (WS), stationary and

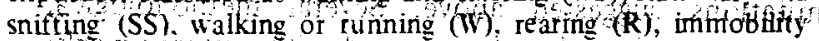
(I). and "grooming (G). Second various beligviors tikety to be' assoviated alja thotional responsiveness awere moasured defecation the open field during the first 2 -min exposure defecation in the $2 \mathrm{~min}$ after the bell, latency to leave the squares adjacent to the walls and enter the center the number of squares' crossed when the bell was sorfinded ("flight distance'), latency of (a) moke the head. (b) move the paws, and (ic) leave

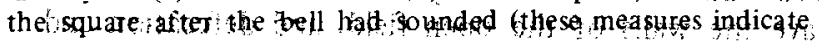
the time spemt "freezing")

\section{Treatment of the Results:}

Analusis! w was iearied out ras follows using itwo-sanple nonparamattic tests: (Siegel, 1956); (1) a preliminary analysis of overall sex differencess all stains and odor conditions combined; (2), the three strains treated separatety: (3) within each strain,

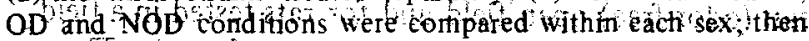
the $e^{2}$ effection sel aifferences of considering $N O D$ and $O D$ conditions sparately atos rexamined Fyar Analyses 1 and 2 , Wilegxon matchedpairs tests were carried out on animals from the same day and the same odor conditions. For Anaty sis 3 animals of the same sex tested on the same day late cotripared again using the Wikcoxor test.

\section{RESULTS TI}

\section{(ai) Overant Sex Differences}

Table a shows the findings for overall sex differences

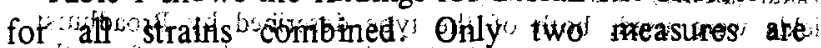
significanty different at the o.05 level mates mo ting to the inner fircles sooper than females and showing more "stationarys snd sniffing", (SS) duting thein tiupe samples. for the first:2 min

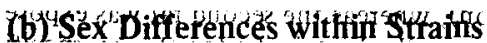

Table 2 shows the sex differences occurking for each

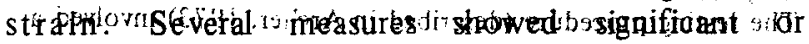
near-significant sex differences for the Sprague-Dawley rats, the males entering the inner circles sooner, defecating less in response to the bell and in theropen field, and showitng more ss during the first 2 min.

Wistars showed no signifteant se dafferences for any measure, whereds Long Evans rats isliowed significhnt differences only! for "walking and "uiffing? (WS), females stow irg mofe than minles. (Malès also showed more $S S$ than $($ ermales, $p=05-1)$

\section{(c) Differencess between NOD and OD Conditions in Relation to Sex Differences}

\section{Sprague-Dawley}

Table 3 shews the differences between rats tested in the-NOD condition and in the OD condition in the open field for the two soxes separately Measures not shown in the table were little different in the two conditions

In males the first four measures shown in Table 3, which are allo likely indications of emotional responsivenes, were higher in the $Q D$ condition than in the NQDione; twor of them significantly so, $\mathrm{No}$ such differonees wete apparent for ithe same measures ity females.

The effect of these two different odor conditions on sex differences is shown in the two right hand columns of Table 3. Rats tested first (NOD) shomed flore pronowned sex! differences, in the four measures than. those tested isecong (QD); significance lavels for sex differences between NOD rats were, therefore, higher than for the two odor conditions combined (Table 2), whereas thase for the QD rats were much reduced and none were statistically significant

\section{Wistan}

Table 4 shows the differences between NOD and ODD conditions for Wistar rats. In contrast to the

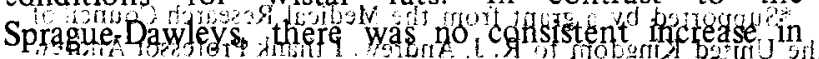
measures of emotional responsiyeness firom the first to the second tested males, but there was a significant increase in defecation following the bell. This difference 
Table 2

Sex Differences in Open-Field Behavior of Three Strains of Rats (Medians)

\begin{tabular}{|c|c|c|c|c|c|c|c|c|c|}
\hline \multirow[b]{2}{*}{ Measure } & \multicolumn{3}{|c|}{ Sprague-Dawley } & \multicolumn{3}{|c|}{ Wistar } & \multicolumn{3}{|c|}{ Long-Evans } \\
\hline & $\begin{array}{c}\text { Male } \\
(\mathrm{N}=20)\end{array}$ & $\begin{array}{c}\text { Female } \\
(\mathrm{N}=20)\end{array}$ & $\mathrm{p}^{*}$ & $\begin{array}{c}\text { Male } \\
(N=20)\end{array}$ & $\begin{array}{l}\text { Female } \\
(\mathrm{N}=20)\end{array}$ & $\mathrm{p}^{*}$ & $\begin{array}{c}\text { Male } \\
(\mathrm{N}=20)\end{array}$ & $\begin{array}{l}\text { Female } \\
(\mathrm{N}=20)\end{array}$ & $\mathrm{p}^{*}$ \\
\hline Latency to inner circle (seconds) & 33.5 & 61.5 & 0.02 & 120 & 120 & n.s. & 46 & 71.5 & n.s. \\
\hline Open-field defecation (boli) & 4 & 5 & 0.056 & 1 & 1 & n.s. & 1.5 & 0.5 & n.s. \\
\hline Walking-sniffing (time samples & 3 & 5.5 & 0.1 & 3 & 4 & n.s. & 5 & 6 & $0.1-0.02$ \\
\hline Stationary-sniffing (time samples) & 4 & 2 & $0.02-0.01$ & 6 & 5 & n.s. & 4.5 & 3.5 & $0.1-0.05$ \\
\hline Rearing (time samples) & 2 & 3 & n.s. & 1 & 1 & n.s. & 1 & 2 & n.s. \\
\hline Grooming (time samples) & 1 & 1 & n.s. & 0 & 0 & n.s. & 0 & 0 & n.s. \\
\hline Immobility (time samples) & 0 & 0 & n.s. & 0 & 1 & n.s. & 0 & 0 & n.s. \\
\hline Bell: defecation (boli) & 0 & 1 & 0.05 & 1 & 1 & n.s. & 1 & 1 & n.s. \\
\hline Bell: flight distance (squares entered) & 5 & 6 & n.s. & 6.5 & 7.5 & n.s. & 8 & 9.5 & n.s. \\
\hline Bell: latency to move head (seconds) & 13.5 & 13 & n.s. & 33 & 36 & n.s. & 23 & 20.5 & n.s. \\
\hline Bell: latency to move leg (seconds) & 23 & 22.5 & n.s. & 63 & 53.5 & n.s. & 98.5 & 40 & n.s. \\
\hline Bell: latency to leave square (seconds) & 101 & 80.5 & n.s. & 120 & 120 & n.s. & 120 & 120 & n.s. \\
\hline
\end{tabular}

*Wilcoxon matched-pairs test, two-tailed probabilities.

Table 3

Behavior of Sprague-Dawley Rats Tested in "No-Odor" (NOD) and "Odor" (OD) Conditions in the Open Field (Medians)

\begin{tabular}{|c|c|c|c|c|c|c|c|c|c|c|}
\hline \multirow[b]{2}{*}{ Measure } & \multicolumn{4}{|c|}{ Males } & \multicolumn{4}{|c|}{ Females } & \multicolumn{2}{|c|}{$\begin{array}{l}p \dagger \text { Value for } \\
\text { Sex Difference }\end{array}$} \\
\hline & NOD & OD & $\begin{array}{c}\text { Median } \\
\text { Increase }\end{array}$ & $\mathrm{p}^{*}$ & NOD & $\mathrm{OD}$ & $\begin{array}{l}\text { Median } \\
\text { Increase }\end{array}$ & $\mathrm{p}^{*}$ & NOD & QD \\
\hline Open-field defecation & 3.5 & 4.0 & +2 & n.s. & 4.5 & 5 & -0.5 & n.s. & 0.05 & n.s. \\
\hline $\begin{array}{l}\text { Median latency to } \\
\text { inner circle (seconds) }\end{array}$ & 27.5 & 48.5 & +18 & n.s. & 61.5 & 62 & +1 & n.s. & $<0.01$ & n.s. \\
\hline $\begin{array}{l}\text { Bell: median flight } \\
\text { distance (squares } \\
\text { entered) } \mathrm{N}=10\end{array}$ & 5 & 7 & +3 & 0.05 & 6 & 5 & -1 & n.s. & & \\
\hline $\begin{array}{l}\text { Bell: median } \\
\text { defecation }\end{array}$ & 0 & 1 & +1 & 0.05 & 1 & 1 & 0 & n.s. & $<0.01$ & n.s. \\
\hline
\end{tabular}

*Wilcoxon matched-pairs test, two-tailed probabilities

†Mann-Whitney $U$ test, two-tailed probabilities

Table 4

Behavior of Wistar Rats Tested in "No-Odor" (NOD) and "Odor" (OD) Conditions in the Open Field (Medians)

\begin{tabular}{|c|c|c|c|c|c|c|c|c|c|c|}
\hline \multirow[b]{2}{*}{ Measure } & \multicolumn{4}{|c|}{ Males } & \multicolumn{4}{|c|}{ Females } & \multicolumn{2}{|c|}{$\begin{array}{l}\mathrm{p} \text { Value for Sex } \\
\text { Difference }\end{array}$} \\
\hline & NOD & OD & $\begin{array}{l}\text { Median } \\
\text { Increase }\end{array}$ & $\mathrm{p}^{*}$ & NOD & OD & $\begin{array}{l}\text { Median } \\
\text { Increase }\end{array}$ & $\mathrm{p}^{*}$ & NOD & OD \\
\hline Open-field defecation & 1.5 & 0.5 & 0 & n.s. & 1.5 & 0 & 0 & n.s. & n.s. & n.s. \\
\hline $\begin{array}{l}\text { Median latency to inner } \\
\text { circle (seconds) }\end{array}$ & 120 & 120 & 0 & n.s. & 120 & 120 & 0 & n.s. & n.s. & n.s. \\
\hline $\begin{array}{l}\text { Bell: median flight distance } \\
\text { (squares entered) }\end{array}$ & 4.5 & 7 & +4 & n.s. & 6.5 & 8.5 & +1 & n.s. & n.s. & n.s. \\
\hline Bell: median defecation & 1 & 2.5 & +2 & $<0.02$ & 2 & 0 & 0 & n.s. & n.s. & $0.1-0.05$ \\
\hline Stationary-sniff (time samples) & 6.5 & 5.5 & -2 & $0.1-0.05$ & 5 & 4.5 & -2 & n.s. & n.s. & n.s. \\
\hline Walk-sniff (time samples) & 3 & 5 & +2 & $0.01 * *$ & 4 & 4 & +1.5 & n.s.** & n.s. & n.s. \\
\hline Immobility (time samples) & 1 & 0 & -1 & n.s. $\dagger$ & 1.5 & 0.5 & -2.5 & $0.08+$ & n.s. & n.s. \\
\hline
\end{tabular}

*Wilcoxon matched-pairs test, two-tailed probabilities $\quad{ }^{*} p$ value for males and females combined 0.02 .0 .01

$t_{p}$ value for males and females combined 0.05.0.02

had only a marginal effect on the separate significance levels for sex differences in NOD and OD rats (Table 4, two right-hand columns).

More striking was the general pattern for both sexes that WS increased and immobility (I) decreased from the NOD to the OD condition. Since these differences were largely common to both sexes, they did not affect the magnitude of the sex difference calculated separately for OD and NOD rats (Table 4, two right-hand columns).

\section{Long-Evans}

Table 5 shows the differences between Long-Evans rats tested under NOD and OD conditions for the two 
Table 5

Behavior of Long-Evans Rats Tested in Clean or Odor-Containing Open Fields (Medians)

\begin{tabular}{|c|c|c|c|c|c|c|c|c|c|c|}
\hline \multirow[b]{2}{*}{ Measure } & \multicolumn{4}{|c|}{ Hales } & \multicolumn{4}{|c|}{ Females } & \multicolumn{2}{|c|}{$\begin{array}{l}\text { p Value for Sex } \\
\text { Difference }\end{array}$} \\
\hline & NOD & $\mathrm{OD}$ & $\begin{array}{l}\text { Median } \\
\text { Increase }\end{array}$ & $\mathrm{p}^{*}$ & NOD & OD & $\begin{array}{l}\text { Median } \\
\text { Increase }\end{array}$ & $\mathrm{p}^{*}$ & NOD & $O D$ \\
\hline Open-field defecation & 3 & 1 & -1 & 0.02 & 1 & 0.5 & 0 & n.s. & 0.05 & n.s. \\
\hline $\begin{array}{l}\text { Median latency to inner } \\
\text { circle (seconds) }\end{array}$ & 47 & 46 & -1.5 & n.s. & 76.5 & 60.5 & -19.5 & n.s. & n.s. & n.s. \\
\hline $\begin{array}{l}\text { Bell: median flight distance } \\
\text { (squares crossed) }\end{array}$ & 9.5 & 7 & -1.5 & n.s. & $?$ & 13 & +4.5 & $<0.01$ & n.s. & .1 \\
\hline Bell: median defecation & 1 & 1.5 & +0.5 & n.s. & 1 & 1.5 & +0.5 & n.s. & n.s. & n.s. \\
\hline Stationary-sniff (time sample) & 4.5 & 5 & +1 & n.s. & 3.5 & 3.5 & 0 & n.s. & n.s. & $.05-.02$ \\
\hline Walk-sniff (time sample) & 5 & 5 & 0 & n.s. & 5 & 7 & +1.5 & 0.02 & n.s. & $.02-.002$ \\
\hline Rearing (time sample) & 1 & 1.5 & 0 & n.s. & 1 & 2 & +1 & n.s. & n.s. & n.s. \\
\hline
\end{tabular}

*Wilcoxon matched-pairs test. two-tailed probabilities

sexes. There was no indication of increased emotional responsiveness from the first to the second tested male rats. as there was for the Sprague-Dawleys. In fact, open-field defecation showed a significant decline from the first to the second tested rat.

Females showed significantly increased "flight distance" and significantly reduced WS from the NOD to the $\mathrm{OD}$ condition (also a significant increase in $\mathrm{R}$ and a decrease in the latency to enter the inner circle).

\section{DISCUSSION}

\section{General Sex Differences in Emotional Behavior}

On the basis of measures such as open-field ambulation and defecation taken over repeated test days, Gray (1971) suggested that male rats are more "emotional" than females. The present open-field measures involved more direct and varied indications of initial emotional responsiveness to novel and startling stimuli; however, they revealed no clear-cut sex differences in emotional behavior throughout the three strains. They, therefore, support the case presented elsewhere (Archer, 1971) that the sex differences discussed by Gray may be more readily explained as several different effects, not necessarily related to initial emotional responsiveness to novel stimuli.

The only two significant sex differences found for all the three strains combined (Table 1) were in SS (stationary sniffing) and in latency to enter the inner circle. Males showed more SS, which is consistent with previous findings that they are generally less active than females (reviewed by Gray, 1971; Archer, 1971). On other measures, however, the males showed no indication of greater emotional responsiveness, which is Gray's interpretation of the activity difference. The present findings that males entered the inner circles sooner than females, despite their lower level of ambulation (measured by WS), is a strong argument against Gray's interpretation of the sex differences in activity.

When data for the three strains were examined separately, there was no evidence that either Wistar or Long-Evans rats showed sex differences in general emotional reactivity. However, Sprague-Dawley males showed significantly lower values than Sprague-Dawley females for three measures associated with emotional reactivity (iatency to enter the inner circle, open-field defecation, defecation following the bell), but there were no significant differences for two other such measures (flight distance and freezing times following the bell). In this strain, therefore, three measures indicated lesser emotional responsiveness by males than by females, the opposite of the general case argued by Gray (1971). It is also interesting to note that open-field defecation (i.e., during the first $2 \mathrm{~min}$ ) was higher for females than males: The reverse has been more generally reported in the literature in studies involving several consecutive trials (reviewed by Gray, 1971). It seems likely that the duration of testing could account for this discrepancy.

\section{Effects of Odors from Conspecific}

Previous studies of sex differences have generally involved little or no control of odor cues, and it is, therefore, difficult to assess the separate sex differences for NOD and OD rats in relation to previous findings.

Male Sprague-Dawleys tested in the OD condition showed higher values for measures of emotional responsiveness than those tested in the NOD condition. One obvious explanation is that the first rat produced a "fear odor" (since it has been startled and induced to flee and freeze by the bell) and that this increased the general emotional reactivity of the second tested rat, as indicated by its higher scores for flight distance, latency to enter the inner circle, and defecation scores. Valenta and Rigby (1968) have shown that Sprague-Dawley rats (sex unspecified) can distinguish between the odors of a shocked and a nonshocked conspecific, but they did not 
investigate whether the odor from the shocked rat acted as an "alarm" or "fear" signal. The present findings suggest that there may be a fear odor in this strain of rat, but further evidence will be required before we can make a more definite and general statement.

These results are also interesting for the way in which they affect sex differences. Sprague-Dawley rats tested in the NOD condition showed clear sex differences in emotional responsiveness (males defecating less in the open field and to the bell and entering the inner circles sooner), but no such differences were found for the OD condition. This result could have important implications for interpreting previous studies of sex differences in this strain, in that an odor from a previously tested male might increase the emotional reactivity of males but females would not be affected by female odor. The precise effect would, of course, depend on the order of testing and how odors from one sex affect the emotional reactivity of the opposite sex.

In contrast to the Sprague-Dawleys, the results for Wistars showed no evidence of a possible "fear odor." Generally, in this strain the differences between NOD and OD conditions had little effect on sex differences. Of more interest was an effect that occurred in both sexes: The second tested rat showed more walking and sniffing (WS) and less immobility (I) and stationary sniffing (SS). Van Oortmerssen (1971), studying mice, also found more extensive locomotion in a novel cage when odor cues from another conspecific were present.

In the Long-Evans strain, females showed more WS and longer flight distances in the OD than the NOD conditions; since the difference in flight distance was not part of a general difference in emotional reactivity (Table 5), these results suggest that the residual odor produced a general increase in motor activity. Since the effect was confined to females, sex differences for the OD and NOD conditions were affected: In the former case, SS and WS were significantly different (less SS and more WS in females), whereas they were not different in the NOD condition.

The results for the Long-Evans rats showed no evidence for a "fear odor." On the contrary, open-field defecation showed a significant decline from the NOD to the OD condition in males but not in females (Table 5). This might possibly indicate that defecation functions as part of a marking system in this sex and strain. Other species of mammals are known to mark their feces with a secretion from anal glands and, in some cases, a territorial marking function has been demonstrated in the male (e.g., in rabbits: Mykytowycz, 1966; Hesterman \& Mykytowycz, 1968). This type of function has also been suggested for defecation in male mice (Collins, 1966: Bruell, 1969; Brain \& Nowell, 1969), but there is no direct evidence at present. A similar form of marking response could account for the present results, in that the first male rat shows general scent marking (feces, urine, and other odor sources) in the clean field and the second one marks to a lesser extent (including defecation) owing to the (inhibiting) effect of the odor from another male. Females would be assumed not to show this response, since they defecated at a lower level in both the NOD and OD conditions. This suggestion must be regarded with caution until further evidence is available, because, in the present study, the feces from the NOD rat were removed and other possible aspects of marking (e.g., urination) were not recorded. However, if confirmed, the finding might influence interpretation of previous results for sex differences in this strain, in that the present data showed that males defecated significantly more than females when tested in a "clean" field (Table 5) but that there were no differences in the OD condition.

In conclusion, the present study found no general overall sex differences in a variety of measures of emotional behavior but did find some sex differences in particular measures associated with emotional responsiveness; these varied with the strain, the measure used, and whether or not an odor from a rat of the same sex and strain was present in the testing apparatus. The findings do not agree with the theoretical position that male rats are more emotional than females (Gray, 1971). Rather, the results were more complex, and a number of factors (discussed above) appeared to be involved. Some aspects of the present findings indicated that odors might be particularly important in this type of research.

\section{REFERENCES}

Archer, J. Sex differences in emotional behaviour: A reply to Gray \& Buffery. Acta Psychologica, 1971, 35, 415-429.

Archer, J. Tests for emotionality in rats and mice: A review. Animal Behaviour, 1973, 21, 205-235.

Beatty, W. W., \& Beatty, P. A. Hormonal determinants of sex differences in avoidance behavior and reactivity to electric shock in the rat. Journal of Comparative \& Physiological Psychology, 1970, 73, 446-455.

Brain, P. F., \& Nowell, N. W. Some behavioral and endocrine relationships in adult male laboratory mice subjected to open field and aggression tests. Physiology \& Behavior, 1969, 4, 945-947.

Broadhurst, P. L. Determinants of emotionality in the rat. I. Situational factors. British Journal of Psychology, 1957, 48. $1-12$.

Broadhurst, P. L. Determinants of emotionality in the rat. If Antecedent factors. British Journal of Psychology, 1958, 49, 12-20.

Bruell, J. J. Genetics and adaptive significance of emotional defecation in mice. Annals of the New York Academy of Science. 1969, 159, 825-830

Cheal. M. L., \& Sprott, R. L. Social olfaction: A review of the role of olfaction in a variety of animal behaviors. Psychological Reports, 1971, 29, 195-243.

Collins, R. L. What else does the defecation score measure? American Psychologist, 1966, 21, 702.

Davies, V. J., \& Bellamy, D. The olfactory response of mice to urine and effects of gonadectomy. Joumal of Endocrinology, 1972, 55, 11-20.

Gray, J. A. Sex differences in emotional behaviour in mammals including man: Endoctine bases. Acta Psychologica, 1971. 35. 29-46.

Gray. J. A.. Levine. S.. \& Broadhurst. P. L. Gonadal hormone 
injections in infancy and adult emotional behariour. Animal Behaviour, 1965, 13, 33-45.

Henderson. N. D. Methodological problems in measuring ambulation in the open field. Psycholosical Reports. 1963. 13. $907-912$.

Hesterman. E. R.. \& Mykytowyzz. R. Some observations on the odours of anal gland secretions from the rabbit. Oryctolagus cumiculus. CSIRO Wild life Research. 1968. 13, 71-81.

Myers. W. J. Critical period for the facilitation of exploratory behavior by infantile experience. Journal of Comparative \& Physiological Psychology. 1962. 55. 1099-1101.

Mykytowycz. R. Observations on odoriferous and other glands in the Australian wild rabbit. Oryctolagus cuniculus (L). and the hare, Lepus europaeus (P). 1. The anal gland. CSIRO Wildlife Research. 1966. 11. 11-29.

Pfaff. D. W.. \& Zigmond. R. E. Neonatal androgen effects on sexual and non-sexual behavior of adult rats tested under various hormoni regimes. Neuroendocrinology, 1971, 7, 129-145.
Siegel. S. Conparametric statistics for the behavioral sciences. New York: McGraw-Hill. 1956.

Stevens, D. A.. \& Koster, E. P. Open field responses of rats to odors from stressed and nonstressed predecessors. Behavioral Biology: 1972, 7. 519-525

Valenta. J. G., \& Rigby, M. K. Discrimination of odor of stressed rats. Science. $1968,161,599-601$.

van Oortmerssen. G. A. Biological significance, genetics and evolutionary orjgin of the variability in behaviour within and between inbred strains of mice. Behaviout, 1971, 38, 1-92.

Whittier. J. L.. \& McReynolds, P. Persisting odors as a biasing factor in open field research with mice. Canadian Journal of Psycholog:', 1965, 19, 224-230.

Woods, P. J. Behavior in a novel situation as influenced by the immediately preceding environment. Journal of Experimental Analysis of Behavior, 1962, 5, 185-190.

(Received for publication May 22, 1973; revision accepted September 4,1973 .) 